\title{
Does Larger Fetal Ascending Aorta Than the Pulmonary Artery Indicate Major Cardiac Anomaly?
}

\author{
Safak Yilmaz BARAN', Alev ARSLAN², Gulsen DOGAN DURDAG', Hakan KALAYCI', Seda YUKSEL SIMSEK, \\ Songul ALEMDAROGLU ${ }^{1}$
}

Adana, Turkey

\section{ABSTRACT}

OBJECTIVE: This study investigated the cases in which the fetal ascending aorta is larger than the main pulmonary artery on the three-vessel view and aimed to determine the relationship between the larger ascending aorta and major cardiac anomalies.

STUDY DESIGN: Pregnancies between 18-24 gestational weeks who underwent detailed secondtrimester screening during 2015-2019 were evaluated. Cases whose fetal ascending aorta diameter was larger than fetal main pulmonary artery diameter on the three-vessel view despite normal four-chamber view were analyzed. Prenatal and postnatal echocardiography studies were performed for each case.

RESULTS: Fetal ascending aorta diameter larger than fetal main pulmonary artery diameter on the three-vessel view despite normal four-chamber view was detected in 21 fetuses in a total of 3810 pregnancies $(0.55 \%)$, and $10(47.6 \%)$ of them had major congenital heart disease. The diagnosis of Tetralogy of Fallot, double outlet right ventricle, ventricular septal defect, pulmonary valve stenosis, and moderate to severe tricuspid regurgitation were confirmed with prenatal/postnatal echocardiography studies. The highest ratio of ascending aorta/main pulmonary artery was 1.4 in a fetus with a double outlet right ventricle and pulmonary valve stenosis.

CONCLUSION: The fetal ratio of ascending aorta/main pulmonary artery larger than 1 on the three-vessel view may be a sign of certain cardiac anomalies. Nevertheless, this rate is not an indicator of a serious cardiac defect in all cases. Fetal advanced echocardiography and early postnatal cardiac evaluation should be done to confirm the diagnosis.

Keywords: Congenital heart disease, Fetal echocardiography, Three-vessel view

Gynecol Obstet Reprod Med 2021;27(2):89-93

\section{Introduction}

Congenital heart diseases (CHD) are the most common cause of congenital malformations. The newborn death caused

${ }^{I}$ Department of Obstetrics and Gynecology, Baskent University Faculty of Medicine, Adana, Turkey

${ }^{2}$ Department of Pediatrics, Divison of Pediatric Cardiology, Baskent University Faculty of Medicine, Adana, Turkey

Address of Correspondence: Safak Yilmaz Baran

Adana Seyhan Baskent Hastanesi, Kadın Dogum Klinigi Gazi Pasa Mah. Baraj Cad.

No: 701140 Seyhan Adana, Turkey

safakyilmazbaran@gmail.com

Submitted for Publication: 11.01.2020 Revised for Publication: 02.02.2020 Accepted for Publication: 12.02.2020 Online Published: 02.08.2021

ORCID IDs of the authors: SYB: 0000-0001-5874-7324

AA: 0000-0003-4444-0027 GDD: 0000-0002-5064-5267

HK: 0000-0003-2054-7102 SYS:0000-0003-3191-9776

SA: $0000-0003-4335-6659$

\begin{tabular}{c|c}
\hline Quick Response Code: & Access this article online \\
\cline { 2 - 2 } 品 & Website: www.gorm.com.tr \\
e- mail: infogorm.com.tr \\
\cline { 2 - 2 }
\end{tabular}

How to cite this article: Baran SY. Arslan A. Dogan Durdag G. Kalayci H. Simsek SY. Alemdaroglu S. Does Larger Fetal Scending Aorta Than the Pulmonary Artery Indicate Major Cardiac Anomaly? Gynecol Obstet Reprod Med 2021;27(2):89-93
CHD is $6-10 \%(1,2)$. In some specific CHD subgroups, with prenatal diagnosis, immediate and correct surgical treatment could be performed in the postnatal period which provides a decrease in newborn deaths (3). The routine evaluation of the fetal heart in the ' 80 s consisted of scanning only four chambers, which resulted in the underdiagnoses of the major cardiac anomalies $(4,5)$. Due to insufficient evaluation, routine echocardiography with vessel outlets, 3 vessels and 3 vessels with tracheal images (3VV-T) were integrated into prenatal scanning (6). The localization and dimensions of the main pulmonary artery (MPA), ascending aorta (AA) and superior vena cava (SVC) can be measured under the three-vessel view $(3 \mathrm{VV})$. In this plane, the MPA is observed on the left, anterior position and slightly larger than the AA. The normal AA/MPA rates are between 0.8-1 according to the gestational week $(7,8)$. However, in some cases, AA could be measured larger than MPA. This measurement is cited as a sign of CHD in the literature (9).

In this study, we aim to analyze the cases with AA larger than MPA in the first fetal heart scanning at second-trimester, which have been confirmed by advanced echocardiography and postnatal echocardiography. 


\section{Material and Method}

Retrospectively 3810 patients were evaluated who had obstetric ultrasound screening between 18-24 gestational weeks at Baskent University Adana Dr. Turgut Noyan Application and Research Center Perinatology Polyclinic between the years 2015-2019. Medical records were extracted from the Hospital Data Management Systems (Version 1.5, Datasel Information Systems, Ankara, Turkey; Nucleus Hospital Information Management System, Version 9.2.40, Monad Software and Counseling, Ankara, Turkey) and patients' files. Twenty-one pregnant who had fetal AA diameter larger than fetal MPA diameter (AA/MPA $>1$ ) at 3VV position, while they seemed to have normal four-chamber view results were included in the study. These cases were confirmed by fetal and postnatal echocardiography.

All ultrasonographic examinations were transabdominal scannings performed by a single operator with Voluson E8 (General Electric Healthcare, Little Chalfont, The UK, 5-8 $\mathrm{MHz} 3 \mathrm{D}$ transducer). In cardiac evaluation, upon capturing a clear $3 \mathrm{VV}$, the image was scaled to the $2 / 3$ of the screen. A satisfactory view demonstrated the following from left to right: MPA in direct communication with the ductus arteriosus, a transverse section of the aortic arch and the SVC. Fourchamber view (FCV), major vein outlets, 3VV, 3VV-T, aortic and ductal arches in the transverse section of the upper abdomen were monitored. When the five-chamber view was evaluated the use of fetal echocardiography, results reinforced cardiac pathologies. The sizes of inner spaces of MPA and AA were measured in a vertical position to ductal and aortic arches respectively (10). A single pediatric cardiologist performed fetal echocardiography with $4 \mathrm{C}$ convex probes and General Electric Vivid S5 (GE Health Medical, Horten, Norway).

Gestational weeks were calculated according to the first day of the last menstrual period of the pregnant women or by considering the ultrasonography that was performed in the first 3 months. Maternal and obstetric features, pregnancy results of the patients, and information about postnatal progress of cardiac defects were obtained from hospital records.

\section{Results}

As a result of obstetric ultrasonographic measurements, there were 21 fetuses $(0.55 \%)$ with AA larger than MPA $(\mathrm{AA} / \mathrm{MPA}>1)$. Major $\mathrm{CHD}$ was observed in 10 of them (47.6\%). Figures 1 and 2 show the cases with the larger AA than MPA on $3 \mathrm{VV}$. Mean sizes of AA, MPA sizes and AA/MPA ratios were detected as $3.6 \pm 1.05 \mathrm{~mm}, 3 \pm 0.97 \mathrm{~mm}$ and $1.2 \pm 0.11$, respectively. Cases in which ascending aorta was larger than MPA on $3 \mathrm{VV}$ are shown in Table I. The highest AA/MPA ratio (1.4) belongs to the case with double outlet right ventricle and pulmonary valve stenosis (DORV-PS).

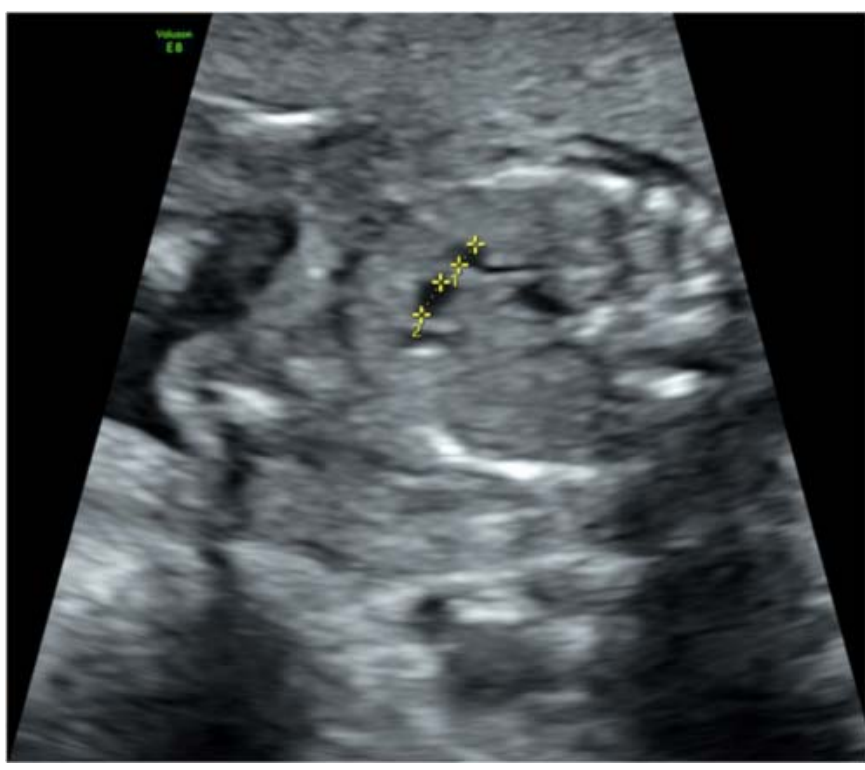

Figure 1: Three vessel view shows that a diameter of ascending aorta larger than a diameter of the main pulmonary artery (1=main pulmonary artery, 2=ascending aorta)

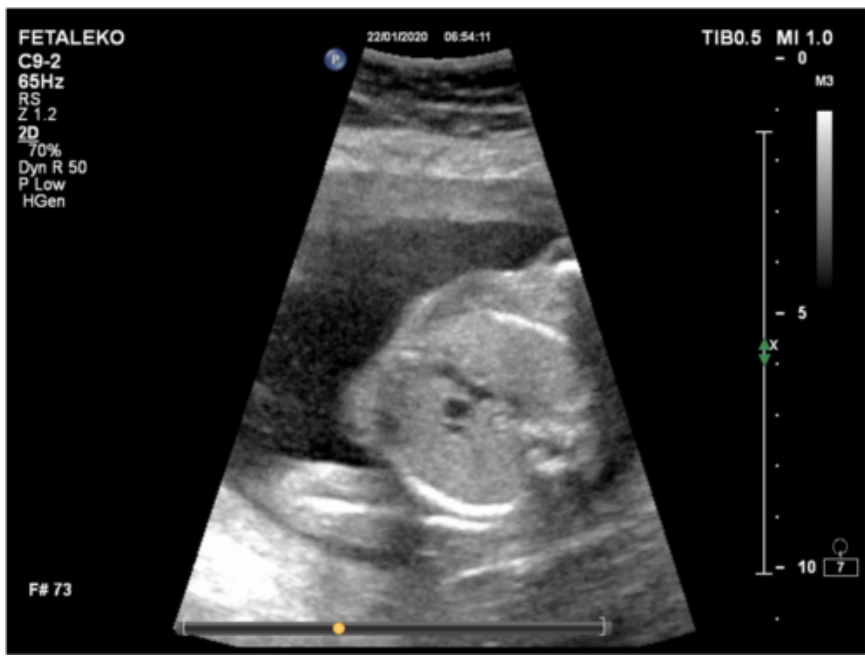

Figure 2: A case of Tetralogy of Fallot with a diameter of ascending aorta larger than a diameter of the main pulmonary artery on the three-vessel view

Mean maternal age at the time of evaluation was $30 \pm 4.0$ years, median gravidity was 2 and parity was 1 . Four cases were multiple pregnancies and 7 pregnancies were achieved by assisted reproductive technologies. The double test was performed to twelve pregnant at first-trimester; all had a low risk for chromosomal anomalies except one. This case had a high risk and was diagnosed trisomy 21 by chorionic villus sampling later. Nine cases didn't prefer to take any tests. The mean gestational week of diagnosis was $20.5 \pm 0.5$ weeks. Cesarean section was performed in 18 pregnancies. Mean birth weight was $2638 \pm 662.7$ grams and mean gestational age at delivery was 36.6 \pm 3.0 weeks of gestation. First minute Apgar score was below 7 in 5 infants and 11 infants were admitted to the neonatal intensive care unit. A pediatrician evaluated all the neonates at birth. Postnatal echocardiography was applied to all newborns before their discharge from the hospital. 
Table II demonstrates features of cardiac anomalies with fetal aorta larger than the main pulmonary artery on the threevessel view. Multiple congenital anomalies were detected in 4 cases. Two infants with severe Tetralogy of Fallot (TOF) had a palliative operation (Blalock Taussig shunt) after birth. Three infants, who were diagnosed as a ventricular septal defect, DORV, tricuspid valve dysplasia, and severe regurgitation, died. These cases had also extracardiac anomalies (intestinal obstruction, multiple anomalies, Zellweger syndrome).

\section{Discussion}

The heart can be considered normal in four-chamber positions especially in outlet VSDs with balanced cardiac ventri- cles and mild degrees of aorta overriding in malalignment VSDs in the early fetal period. The pulmonary artery should be greater than the aorta in the second or third trimester of pregnancy. In fetuses with the ratio of AA/MPA greater than 1 , it needs to be recognized the pulmonary vascular anomaly and increased aortic flow should be recognized (11). Since obstructive lesions of the outflow tracts may progress later in pregnancy, mild to moderate stenosis of great vessels can be misdiagnosed as normal on the $3 \mathrm{VV}$ when evaluated at earlier weeks. In fetal circulation blood flows through the foramen ovale into the left atrium, passes to the left ventricle where it is ejected into the AA. Since both ventricle pressures are equal; an isolated small VSD usually does not cause any significant hemodynamic effects prenatally. Overflow through

Table I: List of congenital heart diseases related with fetal aorta larger than the main pulmonary artery on three-vessel view

\begin{tabular}{|c|c|c|c|c|c|c|c|}
\hline 1 & 20.0 & male & TOF & - & 1.2 & + & Blalock Taussig shunt \\
\hline 2 & 20.3 & male & TOF & - & 1.12 & + & Blalock Taussig shunt \\
\hline 3 & 21.0 & male & TOF & - & 1.10 & + & \\
\hline 4 & 19.5 & male & DORV & PS (Infundibular) & 1.40 & + & \\
\hline 5 & 21.3 & female & DORV & PS (valvuler) & 1.10 & + & \\
\hline 6 & 19.5 & female & DORV & PS, multiple anomalies & 1.10 & + & Neonatal exitus \\
\hline 7 & 20.2 & male & DORV & PS & 1.11 & + & \\
\hline 8 & 20.2 & male & Malalignment VSD & Intestinal obstruction & 1.14 & + & Neonatal exitus \\
\hline 9 & 19.6 & female & Malalignment VSD & - & 1.10 & + & \\
\hline 10 & 20.4 & female & Perimembranous VSD & Secundum ASD & 1.10 & + & \\
\hline 11 & 23.3 & male & Perimembranous VSD & Anal atresia & 1.22 & - & Trisomy 21 \\
\hline 12 & 23.1 & female & Perimembranous VSD & Intestinal obstruction & 1.13 & - & \\
\hline 13 & 21.3 & male & Perimembranous VSD & - & 1.22 & - & \\
\hline 14 & 19.5 & female & Perimembranous VSD & - & 1.15 & - & \\
\hline 15 & 21.3 & male & Perimembranous VSD & - & 1.21 & - & \\
\hline 16 & 20.2 & female & Perimembranous VSD & - & 1.13 & - & \\
\hline 17 & 21.2 & female & Perimembranous VSD & - & 1.20 & - & \\
\hline 18 & 21.1 & male & PS & - & 1.23 & - & \\
\hline 19 & 18.2 & male & PS & - & 1.31 & - & \\
\hline 20 & 19.3 & female & TR & - & 1.21 & - & Translocation carrier \\
\hline 21 & 21.1 & male & Tricuspid dysplasia, TR & Zellweger syndrome & 1.31 & - & Neonatal exitus \\
\hline
\end{tabular}

CHD: Congenital heart defect, TOF: Tetralogy of Fallot, TR: Tricuspid regurgitation, DORV: Double outlet right ventricle, PS: Pulmonary valve stenosis, VSD: Ventricular septal defect, ASD: Atrial septal defect

Table II: Features of cardiac anomalies with fetal aorta larger than the main pulmonary artery on three-vessel view

\begin{tabular}{ll}
\hline Major cardiac anomalies & $10 / 21$ \\
Cyanotic cardiac anomalies & $7 / 21$ \\
Cardiac Operations at newborn & $2 / 21$ \\
- Two cases with Tetralogy of Fallot (Blalock Taussig shunt) & $4 / 21$ \\
Multiple anomalies & $2 / 21$ \\
Chromosomal anomalies & $3 / 21$ \\
- Trisomy 21 & \\
- Translocation carrier & \\
Neonatal exitus & \\
\hline
\end{tabular}


the aortic root causes enlargement of the $\mathrm{AA}$ in moderate to large perimembranous subaortic VSDs. This rate increases especially in pulmonary artery stenosis, which frequently accompanies malalignment VSDs, and some types of doubleoutlet right ventricle. In our series, the aorta was found to be wider on the $3 \mathrm{VV}$ due to the perimembranous subaortic VSD without pulmonary stenosis in 10 fetuses.

Cases with pulmonary stenosis and hypoplasia AA/MPA ratio increase, however in such cases as DORV-PS and Pink Fallot's Tetralogy physiology, which have milder stenosis AA/MPA, may be seen increased in the direction of the aorta in the fetal period. In our study, especially in cases with perimembranous subaortic VSDs and malalignment VSDs with mild aortic overriding, the first finding was greater AA-size rather than hypoplastic- stenotic pulmonary artery in the first cardiac screening. Repeated conventional ultrasound Doppler measurements for pulmonary stenosis progression were performed for each subject.

The reversal of this rate in the absence of VSD necessitates the exclusion of pulmonary valve stenosis and tricuspid valve diseases. Normal forward pulmonary artery flow at the initial examination may be decreased or retrograde flow may occur in association with the development of pulmonary stenosis at tricuspid valve diseases with significant tricuspid insufficiency (12). Therefore, evaluation of tricuspid valve morphology and function, and measurement of pulmonary artery flow with Doppler echocardiography should be performed periodically in patients with abnormal AA/MPA ratio.

In the study of Idilman et al., which is similar to our study, 2540 pregnancies were evaluated and when 17 of those pregnancies with $\mathrm{AA}>\mathrm{MPA}$ on $3 \mathrm{VV}$ were examined, in 5 of them, postnatal normal cardiac results were detected (13). The fact that cases with AA larger than MPA are not necessarily related to a severe CHD is supported by this study as well. Comstock et al. have reported 316 healthy fetuses with a mean 1.09 MPA/AA ratio (0.75-1.43 ranges) in 14-39 gestational weeks. They found 4 fetuses with TOF with the ratio of MPA/AA 0.75, while four fetuses were normal with uncomplicated ventricular septal defects (14). In our study, the cardiac anomaly was detected in all patients with AA/MPA $\geq 1.1$. On the other hand; Rollins et al have evaluated 2797 cases, and found cardiac anomalies in all of 31 fetuses who had AAsize greater than MPA despite a normal 4-chamber view (TOF, TOF variants, aortic valve anomaly, dilatation of AA) (7). Sensitivity and specificity were not evaluated in the Rollins' study similar to our study due to unknown healthy cases with larger AA than MPA at the second-trimester screening that is an important limitation of those studies. However few cases, whose AA is larger than the MPA on $3 \mathrm{VV}$, have been reported in the literature. Therefore, we think that this series will help to consider the possible diagnoses.

In the study of Moon et al. it has been stated that MPA and
AA change depending on the gestational week and physiologically while the diameter of AA is similar or a little smaller than MPA in the second trimester, it remains smaller in the progressive gestational weeks due to heavy right ventricle relative workload (10). For this reason, AA/MPA ratio should be evaluated according to the gestational week and in the progressive weeks, in the case of detection of AA>MPA, it is a must to be precautious regarding fetal CHD.

In the detection of major vessel outlet anomalies, the evaluation of $3 \mathrm{VV}$ together with FCV should be included in the routine perinatal scanning since it can be carried out easily and in a short time $(11,15,16)$. In such cases requesting targeted advanced fetal echocardiography is going to enable the prediction of prenatal CHD's and improve the sensitivity and specificity of abnormal $3 \mathrm{VV}$ in fetal cardiac pathologies (17).

It has also been indicated that simply the scanning parameters are not adequate to diagnose cardiac defects at an early stage and cardiac evaluations consisting of four-chamber view, vessel outlets view and $3 \mathrm{VV}-\mathrm{T}$ have a higher sensitivity $(8,18)$. Additionally, it has been specified that although the FCV and $3 \mathrm{VV}$ are effective in detecting the structural anomalies, they do not suffice in screening valvular anomalies in a multicentric prospective study and such limitations can be overcome through the repetition of fetal cardiac scanning including 30. Gestational week color Doppler evaluation (19).

The result of this study, we detected 21 cases whose fetal AA was larger than MPA on $3 \mathrm{VV}$ despite the normal fourchamber view. The cardiac anomaly was detected in all cases, but only 10 of them $(47.6 \%)$ had a major cardiac defect. In conclusion, fetal sonographic screening of the ratio of $\mathrm{AA} / \mathrm{MPA}$ on $3 \mathrm{VV}$ is important; the ratio is greater than $1 \mathrm{de}-$ spite a normal four-chamber appearance may indicate congenital heart disease. Comprehensive fetal echocardiography should be recommended when the ratio of AA/MPA is found to be larger than 1 on the three-vessel view but it should be kept in mind that it does not always prove a serious cardiac anomaly.

Author contributions: $S Y B$ and AA conceived and designed the project. SYB, SYS, SA and HK collected and analyzed the data. $S Y B, A A$, and $G D D$ wrote and finalized the paper.

Disclosure statement: The authors declare that they have no conflict of interest.

Funding: This study was approved by the institutional review board of Baskent University by the decision number KA19/347 (Approval date: 6 November 2019).

We have taken informed consent for using data from patients and the study was conducted in accordance with the Declaration of Helsinki are needed.

Acknowledgments: We acknowledge to Alp Baran and Can Baran for their invaluable contributions to the manuscript. 


\section{References}

1. Abu-Harb M, Hey E, Wren C. Death in infancy from unrecognised congenital heart disease. Arch Dis Child. 1994;71(1):3-7. doi: 10.1136/adc.71.1.3.

2. Rosamond W, Flegal K, Friday G, Furie K, Go A, Greenlund K, et al. Heart disease and stroke statistics2007 update. Circulation. 2007;115(5):e69-171. doi:10. 1161/CIRCULATIONAHA.106.179918.

3. International Society of Ultrasound in Obstetrics and Gynecology, Carvalho JS, Allan LD, Chaoui R, Copel JA, DeVore GR, et al. ISUOG practice guidelines (updated): sonographic screening examination of the fetal heart. Ultrasound Obstet Gynecol. 2013;41(3):348-59. doi: 10. 1002/uog. 12403.

4. Gardiner H, Chaoui R. The fetal three-vessel and tracheal view revisited. Semin Fetal Neonatal Med. 2013;18 (5):261-8. doi: 10.1016/j.siny.2013.01.007.

5. Wren C, Reinhardt Z, Khawaja K. Twenty-year trends in diagnosis of life-threatening neonatal cardiovascular malformations. Arch Dis Child Fetal Neonatal Ed. 2008; 93(1):F33-F5. doi: 10.1136/adc.2007.119032.

6. Yagel S, Cohen SM, Achiron R. Examination of the fetal heart by five short-axis views: a proposed screening method for comprehensive cardiac evaluation. Ultrasound Obstet Gynecol. 2001;17(5):367-9. doi: 10.1046/j.14690705.2001.00414.x.

7. Rollins RC, Acherman RJ, Castillo WJ, Evans WN, Restrepo H. Aorta Larger Than Pulmonary Artery in the Fetal 3-Vessel View. J Ultrasound Med. 2009;28(1):9-12. doi: 10.7863/jum.2009.28.1.9.

8. Li Y, Hua Y, Fang J, Wang C, Qiao L, Wan C, et al. Performance of different scan protocols of fetal echocardiography in the diagnosis of fetal congenital heart disease: a systematic review and meta-analysis. PLoS One. 2013;8(6):e65484. doi: 10.1371/journal.pone.0065484.

9. Yoo SJ, Lee YH, Kim ES, Ryu HM, Kim MY, Choi HK, et al. Three-vessel view of the fetal upper mediastinum: an easy means of detecting abnormalities of the ventricular outflow tracts and great arteries during obstetric screening. Ultrasound Obstet Gynecol. 1997;9(3):173-82. doi: 10.1046/j.1469-0705.1997.09030173.x.

10. Moon MH, Cho JY, Park EJ, Min JY, Kim JA, Jung SI, et al. Three-vessel view of the fetal heart: In utero development of the great vessels. Prenat Diagn. 2007;27(2):15863. doi: 10.1002/pd.1642.

11. Chen KB, Gu Q, Xia T, Lu X, Zhang ZD. Three-vesseltrachea view in the diagnosis of fetal cardiac great vessel malformation. J Biol Regul Homeost Agents. 2018; 32(2):351-5. PMID: 29685018.

12. Hornberger LK, Sahn DJ, Kleinman CS, Copel JA, Reed KL. Tricuspid valve disease with significant tricuspid insufficiency in the fetus: Diagnosis and outcome. J Am Coll Cardiol. 1991;17(1):167-73. doi: 10.1016/0735-1097 (91)90722-1.

13. Idilman IS, Ipek A, Balaban M, Keskin HL, Aypar E, Ozkutlu S. Fetal aorta larger than the main pulmonary artery on the three-vessel view: Correlation with postnatal echocardiographic findings. J Clin Ultrasound. 2016;44 (7):423-8. doi: 10.1002/jcu.22353.

14. Comstock CH, Riggs T, Lee W, Kirk J. Pulmonary-toaorta diameter ratio in the normal and abnormal fetal heart. Am J Obstet Gynecol. 1991;165(4 Pt 1):1038-44. doi: 10.1016/0002-9378(91)90466-5.

15. Subedi K, Chataut D, Khanal U, Ansari M, Pradhan S. Inclusion of three-vessel view in routine fetal cardiac screening. Nepal Journal of Obstetrics and Gynaecology. 2014;9(1):82-6. doi: 10.3126/NJOG.V9I1.11197.

16. Yagel S, Arbel R, Anteby EY, Raveh D, Achiron R. The three vessels and trachea view (3VT) in fetal cardiac scanning. Ultrasound Obstet Gynecol. 2002;20(4):340-5. doi: 10.1046/j.1469-0705.2002.00801.x.

17. Brandt JS, Wang E, Rychik J, Soffer D, McCann ML, Schwartz N. Utility of a single 3-vessel view in the evaluation of the ventricular outflow tracts. J Ultrasound Med. 2015;34(8):1415-21. doi: 10.7863/ultra.34.8.1415.

18. Riggs T, Saini AP, Comstock CH, Lee W. Comparison of cardiac Z-score with cardiac asymmetry for prenatal screening of congenital heart disease. Ultrasound Obstet Gynecol. 2011;38(3):332-6. doi: 10.1002/uog.8989.

19. Itsukaichi M, Serikawa T, Yoshihara K, Suzuki H, Haino $\mathrm{K}$, Yamaguchi $\mathrm{M}$, et al. Effectiveness of fetal cardiac screening for congenital heart disease using a combination of the four-chamber view and three-vessel view during the second-trimester scan. J Obstet Gynaecol Res. 2018; 44(1):49-53. doi: 10.1111/jog.13472. 